Como citar: FLORES, Nilton Cesar. TERRIBILE, Daniele Regina. Meio Ambiente de Trabalho Sustentável na Construção Civil: A Interface Risco e Direito à Saúde. Revista do Direito Público. Londrina, v.11, n.1, p.41-60, jan/abr.2016. DOI: 10.5433/ 1980-511X.2016v11n1p41. ISSN: 1980-511X.

* Doutor pela Universidade Federal de Santa Catarina; Mestre pela UGF; Coordenador-Adjunto e professor do PPGD - UNESA e Professor do PPGD UNESA. E-mail: cesarflores 2004@hotmail.com

** Doutoranda em Direito pela Estácio de Sá do RJ. Mestre em Direito Público pela UNISINOS. Especialista em Direito do Trabalho e Processo do Trabalho pela IMED/RS. E-mail: dani. terribile@hotmail.com

\section{Meio ambiente de trabalho sustentável na construção civil: a interface risco e direito a saúde}

\author{
ENVIRONMENT OF SUSTAINABLE JOB IN \\ CONSTRUCTION: THE INTERFACE RISK AND RIGHT \\ TO HEALTH \\ * Nilton Cesar Flores \\ ** Daniele Regina Terribile
}

Resumo: O presente estudo analisa o direito à saúde no meio ambiente de trabalho da construção civil, através da perspectiva do risco, prevenção, sustentabilidade e políticas públicas, com ênfase na atividade que expõe o trabalhador à radiação solar e que, por conseguinte, implica em um meio ambiente não sustentável. A análise estará focada no risco ambiental advindo da exposição à radiação e nos seus efeitos legais. Nesse contexto de risco, a prevenção é essencial para a concretização do direito à saúde no local de trabalho, e essa extensão do direito à saúde é fruto de uma leitura constitucional para um meio ambiente sustentável, em especial a partir do art. 196 e do art. $7^{\circ}$, inciso XXII, que faz alusão à prevenção no meio ambiente de trabalho. Nesse contexto, as políticas públicas mostram-se como um instrumento garantidor da prevenção às doenças e da concretização do direito à saúde no ambiente de trabalho. Para esse estudo, utilizaremos a teoria dos sistemas sociais como referencial teórico.

Palavras-chave: Meio ambiente de trabalho. Sustentabilidade. Risco. Direito à Saúde.

Abstract: This study analyzes the right to health in the middle of construction work environment, through risk perspective, prevention, sustainability and public policy, with an emphasis on activity that exposes the worker to solar radiation and, therefore, implies a means not sustainable environment. The analysis will focus on the environmental risk arising from exposure to radiation and its legal effects. In this context of risk, prevention is essential to the realization of the right to health in the workplace, and the extension of the right to health is the result of a constitutional reading for a sustainable environment, particularly from the art. 196 and art. 7, item XXII, which refers to prevention in the working environment. In this context, public policies show up as a guarantor instrument of disease prevention and the implementation of the right to health in the workplace. For this study, we use the theory of social systems as a theoretical framework

Keywords: Half desktop. Sustainability. Risk. Right to Health. 


\section{INTRODUÇÃO}

O direito à saúde é um direito de todos e, quanto a isso não há dúvidas, considerando que foi constitucionalizado em 1988. No entanto, o problema reside justamente na concretização desse direito, em especial, quando se trata do direito à saúde no meio ambiente de trabalho, considerando as perspectivas do risco, da sustentabilidade e a necessidade de políticas públicas de cunho preventivo.

Para tanto, será considerado o paradigma do risco considerando que sua presença é constante na sociedade contemporânea. Em especial, no meio ambiente de trabalho, levando em consideração a agressividade da exposição do trabalhador ao agente radiação solar e, em especial, as consequências dessa exposição ocupacional.

O direito à saúde do trabalhador, no tocante ao câncer ocupacional, é analisado, tradicionalmente, sob ótica das atividades nos ambientes da indústria, que contemplam os riscos do amianto, poeiras de sílica, arsênico, chumbo, manganês, níquel, solventes, tintas, benzeno e outros. Nota-se, então, que as condições de saúde do trabalhador da construção civil não são observadas, ou seja, a concretização do direito à saúde nesse meio ambiente nem sempre é efetivada.

Deste modo, esse estudo analisará as condições em que se efetiva o direito à saúde do trabalhador da construção civil, com foco no câncer de pele decorrente da exposição à radiação solar. A relação do risco com a prevenção para um meio ambiente de trabalho sustentável na construção civil somente se dará com políticas públicas como instrumentos a serviço da prevenção.

\section{O DIREITO AO MEIO AMBIENTE DE TRABALHO SUSTENTÁVEL NA CONSTRUÇÃO CIVIL: A RELAÇÃO DO RISCO COM O DIREITO A SÁUDE}

A análise da prevenção decorre, dentre outras coisas, da presença do risco na sociedade, em especial no meio ambiente de trabalho do trabalhador da construção civil. Concretizar o direito à saúde no meio ambiente de trabalho demanda recepcionar a inegável presença do risco. No que tange à prevenção, pode-se dizer que há uma "preparação" em relação aos danos futuros, não seguros, na qual a probabilidade de existência desses danos diminua a dimensão dos efeitos desse dano. 
Para Luhmann (2008), o risco é um evento generalizado da comunicação, sendo uma reflexão sobre as possibilidades da decisão. Na literatura tradicional, o risco vem acompanhado da reflexão sobre a segurança. Nesta ótica, Luhmann (2008) prefere colocar “o risco em oposição ao perigo, por entender que os acontecimentos sociais são provocados por decisões contingentes (poderiam ser de outra forma), que não permitem mais se falar de decisão segura" (ROCHA, 1998 (a), p. 99). É preciso decidir, e toda decisão gera risco, em especial na questão sanitária; é preciso enfrentar a presença do risco, e na saúde isso é notório, visto que se está lidando com o "bem" vida.

"As doenças, acidentes e mortes no trabalho constituem efeitos indesejados de um modo de produção que elegeu como valor maior a lucratividade e o seu próprio crescimento em lugar do bem estar social". (FIGUEIREDO, 2007, p. 28).

O desenvolvimento econômico não pode ser dissociado da necessidade de proteção dos ambientes de trabalho. Por mais que os processos de trabalho possam ser aprimorados, "o trabalhador deve ter o direito de exercer suas atividades em um meio ambiente de trabalho que lhe possibilite o bem-estar e a vida com qualidade" (ROCHA, 2002, p.129). É nesse contexto de risco que se deve pensar nas questões atinentes à saúde do trabalhador, especialmente no que diz respeito às medidas preventivas.

$\mathrm{O}$ conceito de risco refere-se à possibilidade de danos futuros (dano futuro no meio ambiente de trabalho da construção civil - exposição à radiação solar -: diagnóstico do câncer de pele), devido às decisões particulares (usar ou não filtro solar - prevenir -, por exemplo). São decisões do presente que condicionam o que ocorrerá no futuro. Para se falar em risco, é necessário falar-se de "dano" consequente de uma decisão. Assim, é impossível ter-se segurança frente aos danos futuros.

O conceito de risco tem uma dimensão objetiva, ou seja, toda decisão e todo comportamento podem resultar em risco. Em última análise, pode-se dizer que o risco vincula estados futuros a decisões presentes; é a sociedade controlando a sua própria renovação. (LUHMANN, 2008). O câncer de pele pode ser prevenido a partir de uma decisão do presente, ou seja, fazer uso do protetor solar como EPI, caracterizar a atividade como insalubre e reduzir a jornada de trabalho, eis, então, a prevenção.

Em última análise, pode-se dizer que o que está em jogo é o manejo da quantidade de riscos e da sua importância prática. Talvez a ideia de prevenção 
no ambiente de trabalho seja um reflexo desse manejo. Assim, "gerenciar os riscos" no meio ambiente de trabalho é, também, prevenir. E isso é efetivar o direito à saúde no local de trabalho. $\mathrm{O}$ cerne da questão reside justamente na necessidade de políticas públicas preventivas.

A necessidade de prevenir decorre, dentre outras coisas, da necessidade de gerenciar os riscos. Há a necessidade de um manejo responsável do risco no ambiente de trabalho; o mero "cálculo" de proporção de acidentes e doenças na relação custo/benefício no tocante ao proletariado já não era mais suficiente.

Observa-se que a prevenção aparece nas normas e atos normativos referentes ao direito à saúde no ambiente de trabalho, tem a pretensão de, de forma antecipada, neutralizar ou eliminar o agente agressor por meio de medidas preventivas. Percebe-se que as portarias, resoluções e convenções sinalizam a pretensão de eliminação do risco e, quando isso não for possível, apontam medidas de neutralização. Entretanto, a partir de uma leitura sistêmica, pode-se dizer que é inviável eliminar o risco. Podem-se minimizar os efeitos dele, todavia, elidi-lo é impossível. Veja-se o que diz Rocha:

[...] na sociedade complexa, o risco torna-se um elemento decisivo. O risco é um evento generalizado da comunicação, sendo uma reflexão sobre as possibilidades de decisão. Nesta ótica, Luhmann prefere colocar o risco em oposição com o perigo por entender que os acontecimentos sociais são provocados por decisões contingentes (poderiam ser de outras formas), que não permitem mais falar em decisão segura. Nesta linha de idéias, a sociedade moderna possui condições de controlar as indeterminações, ao mesmo tempo em que não cessa de produzi-las. Isto gera um paradoxo na comunicação. (ROCHA, 2003, p. 104)

No tocante às doenças ocupacionais, a prevenção é amplamente cortejada nas Convenções da OIT e nas Normas Regulamentadoras do Ministério do Trabalho regulamentadas pela Portaria n. ${ }^{\circ} 3.214$, de 08 de junho de 1978 . Tanto as Convenções da OIT quanto as NR's direcionam as medidas de proteção cabíveis às atividades de risco e, se cumpridas através da mobilização dos meios necessários, nomeadamente nos domínios da prevenção técnica, da formação, informação e consulta dos trabalhadores e de serviços adequados, internos ou externos à empresa, são capazes de prevenir as moléstias decorrentes da exposição aos riscos ocupacionais. Para Susssekind (1997, p. 888): 
A vida humana tem, certamente, um valor econômico. É um capital que produz e os atuários e matemáticos podem avaliá-lo. Mas a vida do homem possui, também, um imenso valor afetivo e espiritual inestimável, que não se podem pagar com todo o dinheiro do mundo. Nisto consiste, sobretudo, o valor da prevenção em que se evita a perda irreparável de um pai, de um marido, de um filho, enfim, daquele que sustenta o lar proletário e preside os destinos de sua família. A prevenção é como a saúde. Um bem no qual só reparamos quando o acidente e a moléstia chegam.

A prevenção respalda-se no conhecimento antecipado de determinado risco, em especial sobre os seus efeitos/extensão que, uma vez reconhecido, orienta sua "eliminação" e, se não possível, a adoção de medidas que evitem a exposição humana ao agente agressor. Nesse aspecto, a prevenção às neoplasias malignas é possível de se efetuar se consideradas, primariamente, formas de proteção ao trabalhador exposto à radiação solar no ambiente de trabalho. Essa proteção prescinde de ações de competência legislativa, política e judiciária (sistema da política e do direito).

Contudo, no Brasil, raras, se não inexistentes, são as políticas preventivas ao câncer de pele decorrentes da exposição do trabalhador às radiações solares. As medidas preventivas - políticas públicas - às neoplasias malignas relacionadas ao trabalho são basilares para a prevenção.

\section{MEIO AMBIENTE DE TRABALHO E SUSTENTABILIDADE: AS POLÍTICAS PÚBLICAS COMO INSTRUMENTOS A SERVIÇO DA PREVENÇÃO}

A efetividade do direito à saúde não requer, apenas, a mobilização do sistema da saúde. Políticas e ações intersetoriais, com a mobilização da sociedade e de outros segmentos do poder público, são necessárias. Assim, para se promover e efetivar o direito à saúde de uma população, são indispensáveis criação, promoção, intensificações e concretização de políticas públicas. Ou seja, para a conquista do direito à saúde para todos os membros de uma sociedade (leia-se que todos inclui, também, o direito à saúde no meio ambiente de trabalho) faz-se necessária uma adequada ação intersetorial e as chamadas políticas públicas, especialmente as políticas públicas de cunho preventivo, razão pela qual o direito à saúde deve constar como prioridade na agenda política do país. 
O processo de construção de uma política pública se inicia com a emergência de um elenco de temas - a partir da demanda de grupos de interesse ou da própria burocracia de Estado - para integrar a agenda das instituições políticas. A formulação das políticas públicas "tem no parlamento um lócus fundamental, pois aí se inscrevem as demandas sociais, processamse os conflitos entre os diferentes interesses e são tomadas a decisões de acordo com a hierarquia de preferência dos atores políticos envolvidos"(ROMERO; DELDUQUE, 2011, p. 44). O processo de formação de "políticas públicas é fruto de uma dinâmica de fatores sociais, econômicos, políticos e ideológicos, cuja característica é a complexidade" (SOLA, 1998, p. 36- 39):

Para a formulação das políticas públicas, é necessário que haja planejamento. Embora seja dotado de conteúdo extremamente técnico, não deixa de ser fruto de um processo político. O planejamento é o mecanismo de ligação entre as estruturas política e econômica, pois estão ligadas. (BERCOVICI, 2006, p.146).

Assim, políticas públicas são programas de ação destinados a realizar, tanto os direitos a prestações diretas, quanto a organizações, normas e procedimentos necessários para tanto. Dessa forma, as políticas públicas não são categorias definidas ou estatuídas pelo sistema do direito, mas sim arranjos complexos, típicos da atividade político-administrativa, que "o sistema do direito deve estar apto a descrever, compreender e analisar para, então, poder integrar ao sistema da política os valores e métodos próprios do universo jurídico". (BUCCI, 2006, p. 39). Para BUCCI, as políticas são declarações que descrevem objetivos.

Política pública é o programa de ação governamental que resulta de um processo ou conjunto de processos juridicamente regulados - processo eleitoral, processo de planejamento, processo de governo, processo orçamentário, processo legislativo, processo administrativo, processo judicial - visando coordenar os meios à disposição do Estado e as atividades privadas, para a realização de objetivos socialmente relevantes e politicamente determinados. Como tipo ideal, política pública deve visar a realização de objetivos definidos, expressando a seleção de prioridades, a reserva de meios necessários à sua consecução e o intervalo de tempo em que se espera o atingimento dos resultados. (BUCCI, 2006, p.39). 
Se a política pública visa à implementação, pelo poder executivo, de um comando constitucional, esse comando, no contexto do direito à saúde no meio ambiente de trabalho, tem uma pretensão de cunho preventivo no que diz respeito à própria concretização do direito à saúde. A ordem política concreta forma o quadro dentro do qual se efetiva a política material por meio de estratégias políticas.

Assim, as "políticas públicas são os programas de ação coordenadas para a realização de direitos de prestações” (KOLLING, 2011, p. 22). A previsão constitucional da saúde como um direito de todos e dever do Estado, garantido mediante políticas sociais e econômicas que "visem à redução do risco e de outros agravos e ao acesso universal e igualitário às ações e serviços para sua promoção, proteção e recuperação prescinde de políticas públicas que a efetive" (BUSS, 2002, p. 57). Esse novo desenho constitucional da saúde, fixado em 1988, "representou uma importante base política e democrática para inúmeros avanços institucionais, administrativos e econômicos" (AITH, 2010, p.74).

As políticas públicas destinam-se a racionalizar a prestação coletiva do Estado, com base nas principais necessidades de saúde da população, de forma a "promover a tão aclamada justiça distributiva, inerente à própria natureza dos direitos sociais" (MARQUES, 2007, p. 101-107). Para Dallari (2002, p. 39), “as mudanças sociais não derivam apenas da criação constitucional dos mecanismos que as possibilitem, mas, principalmente, do uso de tais instrumentos".

Ao fixar a saúde como direito de todos e dever do Estado, a Constituição induz a sociedade brasileira em geral, e o Estado em particular, a pesquisar e ampliar seus conhecimentos sobre as melhores formas de organização e gestão do Estado para a efetiva garantia do direito à saúde. [...] Atualmente, a responsabilidade pela prestação de serviços públicos de saúde é do Estado, por meio do seu Poder Executivo, que é responsável por organizar uma rede de serviços públicos de saúde universal e com acesso igualitário. (AITH, 2010, p. 74).

Para Vial (2010, p. 214), "a saúde como um direito será assegurada a partir de políticas públicas". A autora vislumbra que o direito à saúde deva ser "pauta de discussão de direitos mínimos" e também das "políticas públicas de 
saúde, de sorte que a relação entre o Sistema do Direito e da Política possa resultar em Políticas Públicas de Saúde realmente eficazes.

As diretrizes constitucionais de universalidade e integralidade das ações de saúde balizam a construção da política pública correspondente que, por seu arcabouço jurídico sólido, alicerçado na mais alta norma da estrutura escalonada de produção do direito, configura-se como política de Estado, que deve ser observada por todos os governantes, parlamentares e administradores públicos.(MARQUES, 2011, p. 145).

Compreender as políticas públicas como uma categoria jurídica atende à necessidade de busca de concretização/efetivação dos direitos humanos, dentre os quais os sociais, especificamente o direito à saúde e o direito à saúde no meio ambiente de trabalho, também se enquadra nessa leitura, visto que "a partir de uma perspectiva constitucionalizante do direito à saúde, em relação ao meio ambiente de trabalho, nota-se que a prevenção se dará mediante essas políticas" (BUCCI, 2006. p.1-2).

Assim, também deve ser entendido o direito a ter direito à saúde no meio ambiente de trabalho através da previsão constitucional de redução dos riscos inerentes ao trabalho, por meio de normas de saúde, higiene e segurança. Tal efetivação prescinde do executivo a implantação de políticas públicas. A perspectiva do direito à saúde no meio ambiente de trabalho, fruto de uma leitura constitucionalizante, requer medidas de cunho preventivo, haja vista que o risco está presente, também, nesse “ambiente". A exposição à radiação solar abre a possibilidade de futuro diagnóstico cancerígeno; assim, a partir da "conscientização" acerca do risco podemos prever os seus efeitos e minimizálos. Logo, as políticas públicas mostram-se como alternativa ao caminho da prevenção. Esse tipo de política ainda não tem uma tradição no Brasil, já que nunca tivemos políticas públicas focadas, em âmbito nacional, na saúde do trabalhador.

[...] a singularidade da Saúde do Trabalhador, [...], define que nunca se teve, no Brasil, políticas públicas que pudessem ser consideradas como possuidoras do caráter de uma política nacional de saúde do trabalhador. Políticas públicas, sim, vêm sendo experimentadas, pelo menos, ao longo dos últimos 70 anos, mas com um caráter diverso daquele que se considera de Saúde do Trabalhador. Ora pelo setor saúde, até os anos 80, ter estado 
omisso em relação a estas questões, ora em virtude do arcabouço legal ter historicamente responsabilizado as áreas governamentais do Trabalho e Previdência Social por elas, as políticas públicas correlatas foram dirigidas num sentido, pode-se dizer, antagônico ao ideário da Saúde do Trabalhador. (OLIVEIRA; VASCONCELLOS, 2000,p. 4).

Para Oliveira e Vasconcellos (2000), falar de políticas públicas de direito à saúde no meio ambiente de trabalho é falar de políticas de Estado ainda não propriamente experimentadas no Brasil até o início dos anos 90 . Com esta percepção, a reformulação do sistema de saúde brasileiro, estabelecida pela Constituição de 1988 e suas legislações regulamentadoras e complementares, na mesma medida do estabelecimento de diretrizes para uma nova política nacional de saúde, propuseram uma nova configuração da área, "inaugurando uma política nacional de saúde do trabalhador no âmbito do Sistema Único de Saúde" (OLIVEIRA; VASCONCELLOS, 2000, p. 4-5).

Esse novo paradigma é o preventivo, visto que prevenir é propiciar mais saúde e, por conseguinte, mais qualidade de vida. Ampliar essa concepção de saúde para o ambiente de trabalho é, também, concretizar o direito à saúde do cidadão e é, a ainda, reconhecer o valor social do trabalho a fim de dignificar as condições de realização da atividade laboral. Em última análise, a Constituição, por meio do direito à saúde, possibilita a saúde no meio ambiente de trabalho (leitura extensiva e não restritiva). A partir dessa idéia, tem-se o escopo básico para a política pública de prevenção no local de trabalho: a Constituição.

Para Marques, o direito à saúde deve ser garantido, com todas as suas especificidades, de acordo com o artigo 196 da $\mathrm{CF} / 88$, "mediante políticas sociais e econômicas que visem à redução do risco de doenças e de outros agravos e o acesso universal e igualitário às ações e serviços para sua promoção, proteção e recuperação". (MARQUES, 2011, p. 144).

Mesmo em se considerando o estágio incipiente do Sistema Único de Saúde, inclusive como alvo de uma Política Nacional, centrada na sua implantação definitiva e consolidação, a área de saúde do trabalhador encontrou, no enfoque desencadeado pelas novas disposições normativas, inspiradas na Constituição Federal, uma abertura para a formulação de uma Política Nacional específica, a ela dirigida. (OLIVEIRA, 1997-b, p.42). 
Assim, em 1992, o Brasil ratificou a Convenção no 155 da OIT, segundo a qual os Estados-membros devem formular, pôr em prática e reexaminar periodicamente uma política nacional coerente em matéria de segurança e saúde dos trabalhadores e o meio ambiente de trabalho, com o objetivo de prevenir os acidentes e os danos à saúde consequentes do trabalho ou que com este tenham relação, reduzindo ao mínimo, na medida em que for razoável ou possível, as causas dos riscos inerentes ao meio ambiente de trabalho. Nota-se, então, que essa "preocupação" da OIT, regulamentada por meio da Convenção no 155 , é fruto da tomada de consciência do fenômeno do risco.

Incluir a qualidade de vida no meio ambiente de trabalho numa perspectiva preventiva, como política púbica, é um dos desafios. Incluir a qualidade de vida do trabalhador no trabalho, como aspecto de qualidade a ser considerada pelas empresas, com o mesmo apelo atrativo dos mecanismos de incentivo para a melhoria da qualidade, do tipo ISO (International Organization for Standardization), além da motivação pela disputa de mercado. (OLIVEIRA; VASCONCELLOS, 2000, p. 7).

A busca da Qualidade é quase que integralmente orientada para o mercado. Alterações no ambiente exercem enormes influências sobre a natureza e a extensão da operacionalidade no mercado. É essencial, portanto, que a estrutura do planejamento estratégico para a melhoria da Qualidade esteja em conformidade com o ambiente do mercado. (PURI, 2000, p. 8).

Desafio que poderia ser enfrentado com uma política pública nacional de saúde do trabalhador que, por exemplo, contemplasse a criação de um certificado de qualidade de vida no trabalho, conferido às empresas possuidoras de sistemas de controle de riscos que assegurassem a proteção e a promoção da saúde dos trabalhadores. Em função de sua performance comprovada através de procedimentos e indicadores auditados sistematicamente (OLIVEIRA; VASCONCELLOS, 2000, p. 9), as empresas usufruiriam de um alívio progressivo da carga tributária.

Enfim, o desafio de efetivar o direito à saúde no ambiente de trabalho requer a elaboração e implementação de políticas públicas de cunho preventivo às doenças. Para isso, deve-se partir de uma Política Nacional de Segurança e Saúde no local de trabalho capaz de propiciar mais saúde e, por conseguinte, mais qualidade de vida. Também se fazem necessárias iniciativas no sentido 
de se estabelecerem políticas intersetoriais que efetivem as funções de prevenir, promover e fiscalizar a concretização do direito à saúde no local de trabalho. O direito à saúde no ambiente de trabalho, além de ser um comando constitucional, é, também, reconhecer o valor social do trabalho a fim de dignificar as condições de realização da atividade laboral. Assim, o direito à saúde previsto na Constituição deve ser dado através do instrumento das políticas públicas preventivas para que o cidadão possa resguardar sua integridade física e psicológica através da efetivação de um meio ambiente de trabalho sustentável.

\section{O RISCO E A TOMADA DE DECISÃO DO CENTRO DO SISTEMA DO DIREITO}

As organizações são estruturas cuja finalidade é tomar decisões coletivas a partir do código do sistema e da sua programação. Em função das decisões das organizações, o sistema se diferencia do ambiente, permanentemente, e dos outros sistemas. Assim, "o poder judiciário pode ser visto como uma organização voltada à consecução das decisões do sistema do direito” (ROCHA, 2003, p.141).

A constante convocação a decidir é visível no sistema do direito. O centro do sistema (tribunais) precisa decidir, na tentativa de reduzir a complexidade. Entretanto, ao tentar reduzir a complexidade, por meio da decisão, temos um verdadeiro incremento da complexidade.

A matriz sistêmica provoca uma grande mudança epistemológica na teoria jurídica. [...] uma perspectiva autopoiética da sociedade que acentua a sistematicidade do Direito como auto-reprodutor de suas condições de possibilidade de ser. [...] o Direito, embora visto como uma estrutura, é dinâmico devido a sua permanente evolução provocada pela sua necessidade de constantemente agir como uma das estruturas sociais redutoras da complexidade do ser no mundo. (ROCHA, 2003, p. 87-88).

A violação ao direito à saúde no meio ambiente de trabalho decorrente da exposição do trabalhador da construção civil à radiação excessiva é tema que vem buscando respostas do Direito e no Judiciário. As demandas buscam reparação pelo câncer de pele em decorrência dessa exposição e também procuram classificar a atividade como insalubre, através da comprovação de 
laudo de inspeção no local de trabalho que analise as atividades sob radiações não-ionizantes desenvolvidas com a presença de micro-ondas, ultravioletas e laser que, sem a proteção adequada, deveriam ser consideradas insalubres.

A decisão do Tribunal Regional do Trabalho, em pedido de reparação por dano moral e material por doença ocupacional, câncer de pele decorrente da exposição, sem proteção, à radiação solar, na ementa consta que não foi comprovado o nexo de causalidade entre a lesão suportada pelo reclamante e as atividades por este desempenhadas na reclamada, e, portanto, não há que se falar em direito à indenização. Nessa decisão, o juízo do $1^{a}$ grau de jurisdição julga parcialmente procedente a reclamatória trabalhista, condenando a empresa ao pagamento de indenização pelo dano moral no valor de $\mathrm{R} \$ 5.100,00$ (cinco mil e cem reais).

A decisão foi fundamentada na previsão constitucional de que o empregador deve primar pela redução dos riscos inerentes ao trabalho, por meio de normas de saúde, higiene e segurança, a teor do que estabelece o inciso XXII do artigo $7^{\circ}$. O perito nomeado pelo juízo de origem conclui pela existência de nexo de causalidade entre o quadro apresentado pelo trabalhador e suas condições no meio ambiente de trabalho. Essa decisão foi modificada ao ser apreciada pelo juízo de $2^{a}$ grau de jurisdição. O tribunal entendeu que inexiste relação de causa e efeito entre o câncer desenvolvido pelo trabalhador e as atividades por este desempenhadas na empresa. $\mathrm{O}$ tribunal entendeu que o julgador não está adstrito ao laudo pericial do juízo ad quem e decidiu pela não existência de nexo de causalidade entre a doença e o meio ambiente de trabalho.

Esse tipo de decisão demonstra que em alguns casos o decididor não está de fato vinculado ao código do sistema do direito: direito/não direito. A Constituição funciona como mecanismo de acoplamento estrutural entre o sistema do direito e da política. Esse acoplamento permite a comunicação entre os sistemas, sem que haja corrupção, dos códigos binários, entre os referidos sistemas que participam deste processo. Ou seja, o decididor decide usando o código do direito. É um processo de comunicação onde o sistema do direito recebe as informações e as processará em conformidade com o seu código binário próprio, ou seja, direito/não direito. Nota-se, então, que esse processo de comunicação, no caso da decisão referida anteriormente, há uma deficiência, pois o código do direito não está sendo levado em conta na sua integralidade. 
[...] sistema não pode utilizar suas próprias operações para estabelecer contatos com seu ambiente. Todas as operações do sistema são exclusivamente internas. Todas as informações processadas são, exclusivamente, seleções produzidas internamente, a partir de um campo de diferenciação de possibilidades, delineado única e exclusivamente no interior. (NEVES, 1997, p. 41).

Diante dessa ideia podemos observar a função do direito, além do seu modo de operar, da sua racionalidade, considerando o código binário do direito, pois ele recebe e processa as informações e as demandas externas ao próprio sistema jurídico, segundo sua especificidade, "trazendo para o seu interior fechado o (re)processar, conforme o seu fechamento auto referencial e autopoiético" (SCHWARTZ, 2004, p. 29). Esse reprocessar do sistema deve levar em consideração as demandas de saúde, bem como a necessidade de operacionalizar a decisão a partir do código direito/não direito contemplando, assim, um "conceito" de direito à saúde mais alargado, a fim de abarcar o direito à saúde no meio ambiente de trabalho. Assim, observa-se que os sistemas são autopoiéticos (fechados operativamente e abertos cognitivamente), mas não podemos interferir na autopoiese.

A partir do direito à saúde (art. 196 da CF) e a partir do dever de primar pela redução dos riscos inerentes à atividade laboral por meio de normas de saúde (ar. $7^{\circ}$ da CF) seriam a parte do código direito que embasaria a decisão para reconhecer o nexo de causalidade.

As decisões dos tribunais, em relação à agressividade da radiação solar como insalubres, têm entendido que é impossível mensurar se determinada atividade executada sob radiação solar será nociva à saúde devido à falta de limites de tolerância para fundamentar o laudo. Inclusive, o Tribunal Superior do Trabalho editou a OJ - Orientação Jurisprudencial - de n. 173 no sentido de que, em face da ausência de previsão legal, indevido o adicional de insalubridade ao trabalhador em atividade a céu aberto.

A decisão do tribunal pauta-se, unicamente, na inexistência/existência de previsão legal. O julgador, ao aplicar a lei, limitou-se a uma interpretação estritamente legalista. Ou seja, a preocupação na decisão não é voltada ao indivíduo e às agressividades do risco a que se expôs, mas sim, privilegia unicamente uma necessidade de "segurança jurídica", sem considerar, também, os padrões de justiça, pois se não está na lei, não está no mundo dos fatos. 
Para Streck (2010), (ele não está na referencia final com esse ano de publicação) o que não podemos fazer é cumprir a lei só quando nos interessa, ou seja, para o autor o acentuado grau de autonomia alcançado pelo direito e o respeito à produção democrática das normas faz com que se possa afirmar que o Poder Judiciário somente pode deixar de aplicar uma lei ou dispositivo de lei, dentre outras hipóteses, quando:

[...] aplicar a interpretação conforme à Constituição (verfassungskonforme Auslegung), ocasião em que se torna necessária uma adição de sentido ao artigo de lei para que haja plena conformidade da norma à Constituição. Neste caso, o texto de lei (entendido na sua "literalidade") permanecerá intacto; o que muda é o seu sentido, alterado por intermédio de interpretação que o torne adequado a Constituição; [...] (STRECK, 2010, p. 14).

Assim, o julgador, ao decidir sobre o pedido de adicional de insalubridade para as atividades sob radiação solar deverá considerar, primeiramente, o comando constitucional disposto no art. $7^{\circ}$, incisos XXII e XXIII, que estabelecem, respectivamente, a redução dos riscos inerentes ao trabalho por meio de normas de saúde, higiene e segurança e o adicional de remuneração para as atividades penosas, insalubres ou perigosas.

Streck (2009) alerta que introduzir o mundo prático no direito - o que ocorre a partir da diferença ontológica - não quer dizer que basta "jogar" a faticidade "contra" o direito que este se amoldará às demandas do mundo prático. Isso não passaria de represtinação do positivismo fático, onde o direito só se realiza na decisão - isso não é applicatio. (STRECK, 2009, p. 532). A opção por determinada resposta no caso concreto deve ser a que a interpretação melhor acorde com o sentido do direito idealizado pela sociedade.

O pensamento defendido por Streck (2009) é de que a regra jurídica não trata de uma situação concreta/específica, uma vez que diz respeito às inúmeras possibilidades. Inclusive traz como exemplo, em seu livro Verdade e Consenso, que a regra "matar alguém não diz respeito a um homicídio, mas, sim, a como devem ser tratados os casos em que alguém tira a vida de outrem" (STRECK, 2009 , p. 534). Em outras palavras, não se pode conceber as regras como enunciados fechados, pois elas, ao contrário, precisam ser vistas como possibilidade de abertura da interpretação. O caráter de fechamento e de não aceitação de uma maior extensão do intérprete incumbe aos princípios, devendo direcioná-lo, sempre, para a resposta certa. 
Diante desse fato, ao analisar e reafirmar a história de lutas sociais pelas melhorias das condições dos trabalhadores, cabe analisar a questão principiológica, que assim como para Dworkin e Habermas, para Streck (2009) os "princípios são a história institucional do direito e, portanto, não cabem dentro de uma concepção instantaneísta de tempo, pois não podem ser criados a partir de grau zero de sentido"(STRECK, 2009, p. 532).

$\mathrm{O}$ princípio da melhoria social do trabalhador não surgiu do nada. $\mathrm{O}$ legislador, ao inseri-lo no rol dos princípios norteadores do direito, o fez, justamente, pela sua historicidade. Também sequer foi criado por algum critério subjetivo de um ou mais julgadores; muito pelo contrário, o caráter institucional dos direitos sociais permitiu sua criação e existência dentro dos traços democráticos do Estado Democrático de Direito.

Para o trabalhador da construção civil que despende seu esforço físico dia após dia sob intensa radiação solar, há tamanha clareza de sofrimento e nocividade que não haveria necessidade do Estado, através de normas legais, dizer, em letras garrafais, que esta atividade é de extrema lesividade à saúde. O fato de a legislação vigente, a normatização (atos do executivo, portaria 3.214 de 1978) e os julgados não contemplarem a "preocupação" com o direito à saúde no ambiente de trabalho da construção civil que expõe o trabalhador à radiação solar demonstra que temos cidadãos de primeira e de segunda classe; demonstra ainda, que o indivíduo que trabalha na construção civil não tem o direito a ter direito à saúde. Percebe-se, então, que não visualizamos o outro (o individuo que trabalha na construção civil) como o eu.

Decidir pelo reconhecimento do nexo causal entre o adoecimento por câncer de pele e as condições agressivas do meio ambiente de trabalho e, decidir, também, pelo adicional de insalubridade é dar validade social ao direito à saúde. É plausível o juiz decidir pelo nexo causal e pelo adicional de insalubridade (para os casos de exposição à radiação solar), mesmo que esse não tenha sido contemplado pela lei ou até mesmo pela falta de mensuração mais "exata", pois o decididor lida com questões que não estão previstas em lei; entretanto, ele precisa agir como se estivesse obedecendo às leis. A Constituição possibilita liberdade para isso; o direito à saúde e a um meio ambiente de trabalho sustentável, previsto na Carta Magna, é o que permite essa liberdade. 


\section{CONSIDERAÇÕES FINAIS}

A efetivação do direito à saúde no ambiente de trabalho deve os paradigmas saúde, risco, prevenção e políticas públicas. $\mathrm{O}$ trabalho humano contempla, dentre outras coisas, processo de adoecimento do trabalhador causado pelas circunstâncias em que a atividade laboral é desenvolvida. Garantir o direito à saúde no local de trabalho é um modo de dignificar o trabalho e o homem. Alargar a abrangência e o alcance do direito à saúde até o meio ambiente de trabalho sustentável é fruto de um olhar constitucionalizante, a partir do artigo 196 da Constituição da República de 1988, bem como a partir do artigo $7^{\circ}$, que faz expressa menção à redução dos riscos no ambiente de trabalho e indica a necessária adoção de medidas preventivas.

A discussão acerca do direito à saúde ser um direito constitucional e fundamental já não tem mais tanta relevância, visto que já está solidificado o entendimento desse direito como um direito fundamental. O paradigma de discussão está envolto nas facetas do direito à saúde e na sua concretização. Uma dessas facetas é o direito à saúde no meio ambiente de trabalho, fruto de uma extensão da perspectiva constitucional.

A partir da perspectiva do direito à saúde através do meio ambiente do trabalho sustentável e diante da inevitável presença do risco, a prevenção mostrase como alternativa viável e capaz de auxiliar a concretização do direito à saúde no local de trabalho. Essa necessidade advém da tomada de consciência da existência do risco. A saúde do trabalhador está diretamente ligada às variáveis relacionadas ao meio ambiente de trabalho sustentável e resulta diretamente do equilíbrio das condições desse meio.

As políticas públicas são mecanismos concretizadores do direito à saúde e na questão do direito à saúde em um meio ambiente de trabalho sustentável. A falta de especificidade da política pública para a exposição à radiação solar é um impasse à efetivação do direito à saúde. Observou-se que, no tocante ao perfil das decisões do centro do sistema do direito - tribunal -, este não tem decidido pela insalubridade, e há uma resistência muito forte no tocante ao fato de aceitar a comprovação do nexo de causalidade com base no laudo do perito.

Tanto o adicional de insalubridade quanto demais medidas preventivas à exposição do trabalhador à radiação solar devem ser consentidas pela multidimensionalidade dessa realidade, ou seja, a partir da importância econômica que o setor da construção civil demonstrou representar, atualmente, 
para a economia do país. Esse homem deve ser colocado como valor primeiro e objeto da proteção do Estado, não mais podendo ser visto apenas como um elemento no processo econômico; o homem deve ser visto como cidadão, e como tal necessita de saúde, inclusive no meio ambiente de trabalho, somente assim será possível falar em sustentabilidade.

\section{REFERÊNCIAS}

AITH, Fernando. A Saúde como um direito de todos e dever do Estado: O papel dos poderes Executivo, Legislativo e Judiciário na efetivação do direito à saúde no Brasil. In: AITH, Fernando; SATURNINO, Luciana Tarbes Mattana; DINIZ, Maria Gabriela Araújo; MONTEIRO, Tammy Claret (organizadores). Direito sanitário: saúde e direito, um diálogo possível. Belo Horizonte: ESP- MG, 2010. p. 74.

BERCOVICI, Gilberto. Planejamento e políticas públicas: por uma nova compreensão do papel do Estado. In: Bucci, Maria Paula Dallari (org). Políticas públicas: reflexões sobre o conceito jurídico. São Paulo: Saraiva, 2006.

BRANDÃO de OLIVEIRA, Sérgio. A Intervenção do Estado nos ambientes de trabalho: origens, evolução no Brasil e análise crítica da prática da Delegacia Regional do Trabalho do Rio de Janeiro na década de 80. Rio de Janeiro: In: Oliveira, Maria Helena Barros de; Vasconcellos, Luiz Carlos Fadel de. Revista do Centro Brasileiro de Estudos de Saúde: Saúde em Debate. v.24, n. 55, maio/ago. 2000.

BUCCI, Maria Paula Dallari. O conceito de política pública em direito. In: Maria Paula Dallari Bucci (organizadora). Políticas Públicas: reflexões sobre o conceito jurídico. São Paulo: Saraiva, 2006.

BUCCI. O conceito de política pública em direito. In: Bucci, Maria Paula Dallari (org). Políticas públicas: reflexões sobre o conceito jurídico. São Paulo: Saraiva, 2006. p. 31.

BUSS, Paulo Marchiori. Promoção da saúde da família. Revista Promoção da Saúde, Rio de Janeiro, Volume 13, dez. 2002. 
DALLARI, Sueli G. Direito sanitário. Revista Direito e Democracia, Canoas, n.1, v.3, jan. 2002.

ROMERO, Luiz Carlos; DELDUQUE, Maria Célia Delduque. Estudos de direito sanitário: a produção normativa e saúde Brasília: Senado Federal: Subsecretaria de Edições Técnicas, 2011.

FIGUEIREDO, Guilherme José Purvin de. Direito ambiental e a saúde dos trabalhadores. 2. ed. São Paulo, LTr, 2007.

KOLLING, Gabriele; MASSAÚ, Guilherme Camargo. A concretização do direito à saúde na perspectiva republicana. Revista de Direito Sanitário, Porto Alegre, v.12, n.2, jul/out 2011.

LUHMANN, Niklas. The concept of risk. In: A sociological theory. New Jersey: Aldine Transaction, 2008.

MARQUES, S. B.; DALLARI, S. G. A garantia do direito à assistência farmacêutica no Estado de São Paulo. Revista de Saúde Pública, São Paulo, v. 41, n. 2, 2007.

MARQUES, Silvia Badim. Judicialização da saúde e a proposta de regulamentação da integralidade de assistência farmacêutica e terapêutica no Brasil. In: ROMERO, Luiz Carlos; DELDUQUE, Maria Célia (Orgs.). Estudos de Direito Sanitário: a produção normativa e saúde. Brasília: Senado Federal, 2011.

NEVES, Clarissa. B.; SAMIOS, Eva. M. B. Niklas Luhmann: a nova teoria dos sistemas. Porto Alegre: Ed. UFRGS, 1997.

OLIVEIRA, Maria Helena Barros de; VASCONCELLOS, Luiz Carlos Fadel de. Saúde do Trabalhador. Revista do Centro Brasileiro de Estudos de Saúde: Saúde em Debate. Local, v. 24, n. 55, maio/ago. 2000.

OLIVEIRA, M. H. et. al. Análise da Política de Saúde do Trabalhador nos anos 80. Rio de Janeiro/Brasília: Relatório de Pesquisa CNPq. 1997. 
OLIVEIRA, Maria Helena Barros de; VASCONCELLOS, Luiz Carlos Fadel de. Revista do Centro Brasileiro de Estudos de Saúde: Saúde em Debate. Local, v.24, n. 55, maio/ago. 2000.

ROCHA, Júlio César de Sá. Direito Ambiental do Trabalho: reflexos da contemporaneidade. Revista de Direito Sanitário. São Paulo, v. 3, 2002.

ROCHA, Leonel Severo. Direito, cultura, política e democracia. In:

ROCHA, Leonel Severo; STRECK, Lenio Luis; MORAES, Jose Luis Bolzan (Org.). Anuário do Programa de Pós Graduação em Direto Mestrado e Doutorado. São Leopoldo: Editora Unisinos, p.141.

ROCHA, Leonel Severo. Epistemologia jurídica e democracia. 2.ed. São Leopoldo: Editora Unisinos, 2003.

ROCHA, Leonel Severo. Epistemologia jurídica e democracia. São Leopoldo: Editora Unisinos, 1998.

SCHUBERT, Klaus. Politikfeldanalyse: eine einführung. Opladen: Leske + Budrich, 1991.

SCHWARTZ, Germano. O tratamento jurídico do risco no direito à saúde. Porto Alegre: Livraria do Advogado, 2004.

SOLA, Lurdes. Idéias econômicas, decisões políticas:

desenvolvimento, estabilidade e populismo. São Paulo: EDUSP: FAPESP, 1998.

STRECK, Lenio Luiz. Aplicar a "letra da lei" é uma atitude positivista? Novos Estudos Jurídicos, Porto Alegre, v. 15, n.1, 2010. Disponível em: $<$ http://siaiap32.univali.br/seer/index.php/nej/article/view/2308/1623>. Acesso em: 10 dez. 2012.

STRECK, Lenio Luiz. Verdade e consenso: constituição, hermenêutica e teorias discursivas da possibilidade à necessidade de respostas corretas em direito. 3. ed. Rio de Janeiro: Lumem Juris, 2009. 
SUSSEKIND, Arnaldo. Instituições de direito do trabalho. 16 ed. São Paulo: LTR, 1997. v. 2.

VIAL, Sandra Regina Martini Vial. Democracia, direito e saúde: do direito ao direito à saúde. In: STRECK, Lenio Luiz; MORAIS, Jose Luiz Bolzan (org). Constituição, sistemas sociais e hermenêutica: Porto Alegre: Livraria do Advogado Editora; São Leopoldo: Unisinos, 2010.

Artigo recebido em: 28/03/2015 Aprovado para publicação em: 03/03/2016

Como citar: FLORES, Nilton Cesar. TERRIBILE, Daniele Regina. Meio Ambiente de Trabalho Sustentável na Construção Civil: A Interface Risco e Direito à Saúde. Revista do Direito Público. Londrina, v.11, n.1, p.4160, jan/abr.2016. DOI: 10.5433/1980-511X.2016v11n1p41. ISSN: 1980-511X. 